\title{
ESCRITAS DE SI, LITERATURA E CINEMA: DIÁLOGOS (AUTO)BIOGRÁFICOS
}

\section{Apresentação}

[A narrativa] está presente no mito, na lenda, na fábula, no conto, na novela, na epopeia, na história, na tragédia, no drama, na comédia, na pantomima, na pintura [...], no vitral, no cinema, nas histórias em quadrinhos, no fait divers, na conversação. Além disto, sob estas formas quase infinitas, a narrativa está presente em todos os tempos, em todos os lugares, em todas as sociedades; a narrativa começa com a própria história da humanidade; não há em parte alguma povo algum sem narrativa; todas as classes, todos os grupos humanos têm suas narrativas [...]

\section{Roland Barthes ${ }^{1}$}

Na epígrafe, Roland Barthes nos diz que as narrativas, por sua quase infinita diversidade (histórica, literária, biográfica, autobiográfica, cinematográfica...), e por sua onipresença na história da humanidade, representam formas de manifestação inalienáveis do ser humano, onde quer que ele se encontre, não importando o momento de sua vida, e em qualquer tempo histórico. Nessa quase infinita diversidade, os seres humanos encontram nas narrativas biográficas e autobiográficas um modo próprio de ser e de contar a história de vida de outrem (biografia) e a história de sua própria vida (autobiografia), constituindo e constituindo-se enquanto seres sociais, racionais, líricos, históricos, místicos, políticos, artísticos, míticos...

Mas não podemos nos esquecer dos catorze séculos que separam o surgimento dos termos "biografia" (século V) e "autobiografia" (século XIX). Quais as razões de tamanho atraso? Se o primeiro designa um gênero, inicialmente re-

1 BARTHES, Roland. Introdução à análise estrutural da narrativa, In: BARTHES, R. et al. Análise estrutural da narrativa. Trad. Maria Zélia Barbosa Pinto. 7a. ed. Petropólis, RJ: Vozes; 2011, p. 19. servado à vida dos heróis, de dignitários, de personalidades extraordinárias, o segundo, enquanto gênero literário, rompe com essa tradição. Tomando como base o primeiro manuscrito das Confissões (1782) de Jean-Jacques Rousseau, Philippe Lejeune ${ }^{2}$ teoriza sobre uma tripla revolução, inaugurada por Rousseau no século XVII, quando o termo ainda não existia. Uma revolução psicológica (associando intimidade e história da personalidade, em uma nova comunicação entre os indivíduos); uma revolução literária e estética (assumindo uma nova linguagem para falar de si); uma revolução social e política (destacando o valor exemplar da experiência do indivíduo, independentemente de sua posição social e mesmo de seu grau de escolaridade).

Essa tríplice revolução abre passagem para as pessoas comuns se tornarem autores e personagens de suas histórias, nas mais diversas modalidades de narrativas autobiográficas (diários íntimos, cartas, anotações pessoais, autobiografias, projetos de vida), quer se tornem ou não obras literárias. O que de fato é significativo nessas escritas de si é, por um lado, a garantia de que a história se apoia nas ficções ou verdades de uma pessoa concreta, e para quem narra suas experiências, sonhos, devaneios, decepções e esperanças é pelo ato de biografização, que ela consegue assim melhor compreender a vida e se compreender como ser vivente.

Se até os anos de 1980, essas narrativas (auto)biográficas eram consideradas, pela ciência e o mundo universitário, como gêne-

2 Philippe Lejeune. Definir autobiografia. Disponivel em: <http://www.comparatistas.edu.pt/>. Acesso em: 3 ago. 2016. 
ros menores porque impregnados de subjetividade, elas explodem, a partir de então, no mercado editorial, em contextos acadêmicos, e se consagram cada vez mais como fontes de pesquisa e dispositivos de formação em Educação. Elas se inserem, então, definitivamente, no mundo científico e universitário, que se configuram, em geral, avessos à intuição, à subjetividade e à emoção.

Este segundo dossiê da Revista Brasileira de Pesquisa (Auto)Biográfica - RBPAB apresenta uma diversidade de textos e abordagens que contracenam com o biográfico e o autobiográfico, em literatura, cinema e formação. Um dos seus principais propósitos é que a sua leitura sinalize para novos horizontes de investigação científica, no âmbito da pesquisa (auto)biográfica em Educação.

0 artigo que abre este dossiê, Do sussurro ao grito: escritos autobiográficos de Carolina Maria de Jesus e Maura Lopes Cançado, de autoria de Gislene Maria Barral da Silva e Mônica Horta Azeredo, se inscreve na perspectiva de uma dupla virada (auto)biográfica. A primeira, no âmbito das narrativas de mulheres, "até então silentes", e, a segunda, que considera o registro de diários íntimos (um escrito na favela, e outro no hospício), matéria de reflexão científica, histórica e literária. As autoras do artigo, com base nos estudos de Mikhail Bakhtin e Philippe Lejeune, analisam duas obras literárias dessas autoras brasileiras, de origem social e nível de escolaridade, diametralmente opostos, mas apresentando em comum o mesmo "desejo de gritar suas dores ao mundo". o artigo ressalta a importância política de Quarto de despejo. Diário de uma favelada, de Carolina Maria de Jesus (1914-1977) e Hospício é Deus, de Maura Lopes Cançado (1929-1993). As escritas autobiográficas, para essas duas mulheres, são modos de resistência e de empoderamento, pois elas extrapolam os limites da intimidade de suas vidas, em seus diários, para traçar, com as cores do seu cotidiano, os retratos de outras tantas mulheres, habitantes de favelas, catadoras de papel, ou mulheres da elite que, no seio de uma sociedade opressora e machista, buscam formas de resistência, mesmo que ela seja a situação limite do hospício e da loucura.

Considerando ainda como fonte autobiográfica o diário íntimo, transformado em obra literária, o artigo Memória feita de retalhos: subjetividade em crise e vida cultural na Belle Époque, de Carmem Lúcia Negreiros de Figueiredo, apresenta uma análise da obra Retalhos, do escritor brasileiro Lima Barreto (1881-1922), como uma mescla de registros de seu cotidiano. O foco do artigo é discutir a intensificação da vida moderna e da subjetividade em crise. Nesse diário feito de "retalhos", Lima Barreto vai colando e comentado fragmentos de jornais, folhas de livros, excertos de crítica literária, observações do cotidiano, que ele colecionava, para, com eles, narrar sua vida e se configurar como sujeito, colecionador, que busca, nesses "retalhos", sentidos para os acontecimentos que marcaram a belle époque brasileira.

O questionamento da crise de identidade do eu, que se alarga para a crise da memória cultural, subjacente ao texto de Lima Barreto, retorna sob outro enfoque no artigo de Sheila Dias Maciel, As duas memórias de um escritor, que analisa dois livros autobiográficos de Carlos Heitor Cony, Quase memória: quase-romance (1995), e Eu, aos pedaços: memórias (2010). A autora nos provoca a pensar que escritores como Cony ordenam o eu, "despedaçado", em seus textos, a partir de visões que produziram de si mesmos, numa dupla retomada do passado, sob uma forma confessional. Além de apresentar as diferenças entre as duas obras, Sheila Maciel volta-se para a necessidade autoral de se refazerem as memórias, no contexto de uma sociedade que se ocupa, cada vez mais, das ambivalências entre permanência, decadência e descarte. 
Rodrigo Matos de Souza e Elizeu Clementino de Souza, em seu artigo A (de)formação pela escola: representações de processos formativos na trilogia autobiográfica de Elias Canetti, analisam a trilogia autobiográfica de Elias Canetti (1905-1994): A língua absolvida (2010), Uma luz em meu ouvido (2010) e 0 jogo dos olhos (2010), instigando-nos a pensar sobre questões éticas do mundo de quem ensina, bem ao sabor do que o título propõe: a (de)formação pela escola. Os autores, à luz da teoria melichiana, analisam as representações do mestre (maestro) e do aluno, para ressaltar os propósitos de Canetti, que compôs, em sua escrita autobiográfica, uma visão de sua formação escolar e acadêmica, para além de seus paradigmas mais frequentes, para evidenciar temas formativos. Destacam, na análise, a relação professor-aluno, abordada por Canetti, discutindo a oposição entre o dizer (do professor) e o mostrar (do mestre), como formas de (des)encantar o aluno. 0 que deduzem dessa diferenciação é que o mostrar traz consigo a ética, a estética e a religião, aspectos centrais da transformação na vida humana ou da (de)formação pela escola. Concluem que esses aspectos só podem ser aprendidos com base no que eles nos afetam, e não com base no dizer, na demonstração de uma teoria científica, eles só podem ser "mostrados" e não demonstrados.

Nima Imaculada Spigolon, no artigo, "Escritos intimos" e escrita de si: por entre as páginas e a vida de Elza Freire, revela a muIher Elza Maia Costa Oliveira, esposa de Paulo Freire. Nima Spigolon constrói Escritos Íntimos com um conjunto de fontes que vem reunindo sobre Elza Freire, desde 2006. Neste artigo, a autora se debruça sobre o caderno de receitas de Elza, discutindo como nele ela se esconde, ou se protege, e, ao se posicionar "criticamente, tece comentários políticos, analisa conjunturas [...] para depois colar receitas, dentre elas: Pato (marreco) assado com laranjas e Pastelão de frango". As indagações de Nima Spigolon, com base em "Escritos Íntimos", são estimulantes para a pesquisa: como esse caderno revela e esconde uma mulher que vivia à sombra, "sem formas e lugares para manifestar-se? Será que eram marcas da educação familiar tradicional nordestina? Da condição de mulher? Da percepção das possibilidades de desintegração da família, nos contextos de ditadura e de exílio?" São muitas as questões e ainda poucas as respostas sobre as contribuições político-pedagógicas de Elza Freire ao legado de Paulo Freire. Desta forma, lançar mão das escritas de si contidas em "Escritos Íntimos" é lançar-se na intenção de dar visibilidade aos movimentos silenciosos e silenciados, que atravessam e forjam os percursos formativos-acadêmicos, como possibilidade de potencializar a discussão epistemológica acerca do métier acadêmico.

A arte cinebiográfica constitui a fonte de reflexão dos dois próximos artigos num exercício de aproximar as práticas narrativas autobiográficas da filmografia. Vivian Braga dos Santos, em Como autobiógrafo e historiador: episódios de uma história sul-africana por William Kentridge, analisa com base na série de vídeos que compõem Nine Drawings for Projections (1989-2003), de William Kentridge (Joanesburgo, 1955), o ofício de narrador desenvolvido por artistas contemporâneos que se posicionam politicamente com relação à história do passado recente. A autora discute na arte em questão o retorno de objetos do cotidiano e, notadamente, de duas personagens dos filmes, Soho Eckstein e Felix Teitlebaum. A perspectiva autobiográfica manifesta-se neles como alter ego do artista. Soho testemunha ao espectador experiências no ambiente segregacionista sul-africano, de modo semelhante àquele da composição de uma literatura de testemunho. Já Felix Teitlebaum sugere uma narrativa sobre a modificação do cenário po- 
lítico. A partir desses personagens, observamse dois tipos de relações entre Kentridge, seus personagens e a história política da África do Sul. A primeira delas pode ser entendida como uma posição autobiográfica, a segunda como uma aproximação com o ofício do historiador. Vivian Braga salienta que Kentridge abstémse, todavia, de uma "possível filiação a uma figura messiânica", mantendo, como um sujeito multifacetado, uma posição dual entre papéis distintos, não apenas entre Soho e Felix, mas, sobretudo, entre autobiógrafo e historiador.

o segundo artigo, Limites do eu: o gesto autobiográfico no cinema de Jean Eustache, de Romero Fidelis de Souza Maciel, visa analisar o gesto autobiográfico de Eustache que é pulverizado na sua filmografia, entre curtas e longas-metragens, até longas de ficção, passando pelo documentário. Romero Maciel analisa, na linhagem de narrativas ditas autobiográficas de Jean Eustache, os modos como o cineasta "rompe com o princípio de sistematização do eu em sua filmografia" e vai embaralhando gêneros, deixando ao espectador o trabalho de construir a teia de referências autobiográficas. A aparente falta de unidade, na produção do autor analisado, sugere uma singularidade no âmbito da cinebiografia, daí a importância de se perceber como os seus filmes apontam para uma subjetividade que faz de sua própria fragmentação uma assinatura estilística consciente. Entender a maneira como Jean Eustache representa-se neste campo do cinema e da autobiografia, ao colocar à prova suas fronteiras, é o propósito dessa análise. Vale conferir o intento do autor.

0 artigo de fechamento deste Dossiê, Escrever a própria vida: aspectos estilísticos do gênero diário pessoal, de Jocelma Boto Silva e
Marcia Helena de Melo Pereira, retoma a escrita do diário íntimo para discutir aspectos teóricos e estilísticos das escritas de si sob a forma de diário. Contrariamente aos textos anteriores que, neste Dossiê, focalizam diários de escritores consagrados, ou diários que se transformaram em obras literárias, Jocelma Silva e Marcia de Melo analisam dois diários, não publicados, de duas jovens mulheres: o diário de $\mathrm{K}$ (que escreve desde criança) e o de $\mathrm{C}$ (que começa a escrever aos 28 anos, depois de uma crise no casamento). As autoras do artigo nos instigam a pensar sobre a flexibilidade das formas que adquirem essas escritas de si, ampliando as bases dos estudos de Bakhtin e de Lejeune sobre as narrativas do eu. Nas análises, que são complementadas em entrevistas realizadas com as duas diaristas, as autoras do artigo evidenciam como os diários analisados se distinguem, sob vários aspectos, desde a concepção formal e estrutural do gênero até a função que eles representam para as escreventes.

Contrariamente à visão canônica das Ciências Humanas, as narrativas autobiográficas, sob a forma de diários, de cinema e da literatura, revelam que elas são bem mais propícias à compreensão do humano e de suas circunstâncias.

Boa leitura! Natal-Porto Alegre, agosto de 2016

Maria da Conceição Passeggi
Universidade Federal do
Rio Grande do Norte

Edla Eggert

Pontifícia Universidade Católica do Rio Grande do Sul 